\title{
REGISTROS REALES DE LOS SIGLOS XIII-XIV EN EL ARCHIVO MUNICIPAL DE ALCOY
}

\author{
RICARD BAÑÓ ARMIÑANA
}

El Archivo Municipal de Alcoy (AMA) contiene una gran riqueza archivística. Sus fondos se extienden cronológicamente desde el año 1263 (Llibre d'Extravagants, anys 1263-65) hasta nuestros días.

Los registros más numerosos, refiriéndonos a la época foral, pertenecen a la serie del «Cort del Justícia» que cronológicamente abarcan el período 1308-1705, habiendo pocas lagunas de años, siendo estas faltas escasas a partir del siglo XVI.

Es lógico que entre tanto material documental el campo de investigación, no sólo a nivel local sino a nivel de Reino de Valencia histórico, es inmenso. Yo he querido ofrecer en este trabajo una de esas posibilidades de investigación: el de los registros reales durante los siglos XIII-XIV. Por supuesto que no son todos los que hay, al menos reflejo los que yo he encontrado, pero son una expresión de esa riqueza de la que he hablado antes. Estos 19 registros son en buena parte, o todos, inéditos, y yo destacaría de entre ellos el número $1 .^{\circ}$, por tratarse de un documento de Jaime I que no aparece en la relación de HUICl-CBANES. Habría que añadirlo a los 13 que encontré en el Archivo Municipal de Cocentaina (Revista del Instituto de Estudios Alicantinos, ${ }^{\circ}{ }^{\circ} 29$, pp. 97-112).

Desde el punto de vista paleográfico he seguido las normas contenidas en el volumen «Elementos de Paleografía» (Valencia, 1972) de Cabanes Pecourt. Por lo que respecta a la toponimia y a los gentilicios he respetado la lengua autóctona del País Valenciano. En el caso de "Alcoy», aunque las normas lingüisticas prefieran «Alcoi», he optado por la grafía histórica y, por ende también correcta. He utilizado (...) para la(s) palabra(s) que no se pueden 
leer, casi siempre a causa de la humedad que afecta al folio, o las que yo no he sabido transcribir, ${ }^{\circ}(.$.$) cuando la dificultad de lectura se ha debido$ a un agujero en el papel, y ( ) para mis anotaciones. El final de línea viene representado por / y el final del folio por // seguido de la numeración del folio siguiente.

\section{$-1-$}

1249, julio 31. Valencia

Jaime I, rey de Aragón, extiende el privilegio de enfranquimiento otorgado a Ponç Guillem de Vilafranca del Conflent a sus sucesores

AMA. Cort del Justícia 1313, fols. $33 r-34 v$

Hoc est translatum bene et fideliter sumbtum a quodam privilegio domini Jacobi regis Aragonum felicis / recordacionis, scripto in pergameno sigillato cum suo sigillo ceree rubeo pendulo $\mathrm{XV} .{ }^{\circ}$ kalendas madii / anno Domini millesimo $\mathrm{CC}^{\circ}{ }^{\circ}$ nonagesimo tertio cuius series sic habetur:

«Novernt universi quod nos Jacobus Dei / gratia rex Aragonum, Maioricarum et Valencia, cometis (sic) Barchinone et Urgelli et dominus Montispesulani / per nos et nostros concedimus de gratia speciali tibi Poncio Guillelmi de Villafrancha de Conflent et tuius, quod / illo privilegio quod nos tibi iam concessimus de franquitate henda super hereditatibus et possessionibus // (fol. 34v) tuis et tuorum (...) omnes filios et $(.) /.(\ldots)$ et spurios qui $(\ldots) /$ alia qualibet racione (...) et (...) Va / lencie vel inquocumque (...) quam aliorum (...) fran $/$ quas (?), liberas et quietas (...) quod in dicto privilegio per nos tibi iam concesso (...). Et etiam / concedimus ills omnes alias franquitates qui predicto privilegio sunt per nos tibi (...) / baiu / lis, iusticiis, porteriis et omnibus aliis oficialibus nostris presentibus atque futuris quod predicto omnia (...) / observent et observari facere et faciant si in nostra gratia et amore confidunt.

Datum Valencia Il / kalendas augusti anno Domini Millesimo CC XL nono./

Sig(signo)num Dominici de Cepillo notarii publici Cocentaine et curie eiusdem, testis».l

Sig(signo)num A. de Pina, iusticie Cocentaine qui huic translato suam presticit auctoritatem et (...)./

Sig(signo)num Geraldi de Torroelles, notarii publicii Cocentaine, qui hoc scripsit et bene et / fideliter translatavit et a suo originali comprobavit et clausit die et anno predicto. 


\section{8 (1), febrero}

Jaime II, rey de Aragón, otorga privilegio de enfranquimiento a la villa de Castalla, a causa de los avatares sufridos por ella en la guerra contra Castilla, a condición de que habiten y pueblen el arrabal de dicha villa

AMA. Cort del Justícia 1333, sin foliar

Açò és tresllat bé e felment transllatat secunda nonas marcii anno Domini Millesimo CCC. ${ }^{\circ} /{ }^{\circ}(..) \mathrm{X}$ d'un privilegi scrit en pergami sagellat ab lo sagell del senyor rey de plo $l^{\circ}(\ldots)$ ab fils de seda grochs e vermells, la tenor del qual és aytal:

«Nos Jacobus / Dei gratia rex Aragonum, Maioricarum, Valencie et Murcie, comesque Barchinone ac sancte ro / mane ecclesie vexillarius, amirantus et capitanus generalis, atendens dampna que vos, homines / nostri de CastaIla, ratio guerre quod fuit et est inter regna nostra et Castelle sustinuistis et / cotidie etiam sistinetis ad augmentum et melioramentum loci predicti totaliter in $/(\ldots)$ per nos et successores nostros enfranquimus et liberos, franchos et inmunes / facimus in perpetuum vos omnes homines predictis de Castalla presentes et futuris, habitantes et / habitaturos in loco predicto ab omni questia, peyta, subsidio, servicio, cena, monecatico, exer / citum et cavalcata, lezda, pedagio, mensuratio, portatico tam per marem quam per terram / ab omni alia exaccione et iure regali que dicti nominarii possint seu etiam congitari et / redemptionibus eorundem.

Ita quod vos vel vestri in loco predicto habitantes et habitaturi non teneamini nobis aut nostris aliquo tempore aliquique solvere predictis vel aliquo pre / dictorum hoc tamen enfranquimentum et inmunitatem vobis facimus sub hac condicione / quod vos et vestri presesentes et futuris teneamini vos populare ac etiam habitare et // morari in ravali dicti loci et si omnes non posetis modo vel imposterum vos in ravali predicto populare seu etiam habitare que ad cognitione baiuli nostri vel nostrorum ge / nerale Regni Valencie qui pro tempore fuerint populetis vos et habeatis in villa nostra, loci / predicti subtus ravale predictum constituta et non in alio loco pro ut dicto baiulio melius (?) / ad comodum et utilitatem nostram visum fuerit expedire. Mandantes procuratoribus, iusticiis, baiuliis, portaticis, collectoribus, lezdariis, pedagiariis et universis a /

(1) Por el contexto del documento doy por válida la cifra «séptimo» de la data y lo fecho enn 1298, año en que el Reino de Valencia y el de Castilla están en guerra por el asunto de la conquista del Reino de Murcia. 
liis officialibus nostris presentibus ac futuris quod predictam concessionem nostram presentibus ac futuris quod predictam concessionem nostram / fimam habeant, observent et non contraveniant nec aliquem contravenire permi / tant (?) aliqua ratio.

Datum apud ${ }^{\circ}(\ldots)$ idus februarii anno Domini Millesimo CCC. ${ }^{\circ}$ (sic) ducentesimo (sic) septimo.

Signum (signo) Jacobi Dey gratia rege Aragonum, Maiori / carum, Valencie et Murcie, comesque Barchinone ac sancte romane ecclesie vexillarius, amiranti / et capitanei generalis./

Testes sunt Jazbertus de Castronovo, Philipus de Soluciis, Jacobus Petri Gondiçalbus, / Eximini Darenoso, Dalmacius de Castronovo./

Sig(signo)num Petri Marti scriptoris domini regis cuy mandato eiusdem hoc scribi, fe / cit et clausit die et anno (...) supran./

Senyal (signo) d'en Jacme Destadella notari de Castalla (...) aquest tresllat del horiginal / feelment de punt a punt treslatí e scrivi en lo dia e any desus dit e cloy.

\section{$-3-$}

1307, agosto, 17. Barcelona

Jaime II, rey de Aragón, nombra, a instancia de na Saurina de Entença, a Gombau de Entença tutor de Carleto y de Berenguer, hijos de Roger de Llúria y de la dicha na Saurina.

AMA. Cort del Justícia 1308-10, fol. 20r - v

Pateat universis quod nos Jacobus / Dei gratia regi Aragonum, Valençia (sic), Sardinie et Corcissise (sic), comittique (sic) Barchinone ac sancte / romane ecclesie vexillario, amiranto et capitaneo generali, ex parte nobilis Saurine de / Loria, uxoris quondam nobilis Rogerii de Loria, amiranti nostri, fuit expositum et ostensum / quod cum dictus nobilis Rogerius decesserit relictis Karleto et Berengario impuberibus filiis / comunibus dictis Rogerio et Saurine nulio relicto eis tutorem et sedulum petendi // (fol. 20v) tutoris oficium sit a matribus exigendum et dicti filii tutoris remedio sibi et bonis suis e / geant necessario providire. Idcirco nostris fuit ${ }^{\circ}(. .$.$) ex parte dicte nobilie Saurine / humiliter su-$ plicatum ut dictis impuberibus nobile Gombaldi de Entença, avunculum / dictorum impuberum et consanguineum dicte nobilis Saurine, in tutorem detinere de / beremus. Nos igitur dicte nobilis dompne Saurine suplicatione ut iuri 
con / suna benigne admissa dictum nobilem Gombaldum de Entença, licet absentem, / in tutorem constituimus et decernimus Karleto et Berengario impuberibus supradictis, / licet absentibus. Volumus tamen et mandamus quod dictus nobilis Gombaldus permitet / et idonee pro rey qualibet sacesdet inposse Bernardi Dalmacerus, iusticie Valencie, publico notario, / nomine dictorum impuberum et eorum ominum quorum interest vel interesse possit stipulanti / et recipienti et iuret ad sacta Dei evangelia manibus eius corporaliter tacta omnia / et singula dictorum impuberum utilia facere et inutilia pretermitere et eorum personas, et res / bona fide custodire et inventarium facere de rebus eorum et administrationis sue / tempore debito reddere racionem cum intengra ressiduorum restitutione antequa actingat / administrationis dicte tutelle. Nos enim fidei et legalitati sue comittimus tutellem (?) / predictam cum testimonio presentis carte notre sigillo apendicio roborare. Mandates per presentem cartam omnibus oficialibus et subditis nostris ut dictum nobilem Gombaldum / de Entença pro tutore dictorum impuberum habeant et eidem de bonis eorum ut tutori faciant (...).

Actum Barchinone $\mathrm{XV} I^{\circ}$ kalendas setember anno Domini $\mathrm{M}^{\circ} \mathrm{CCC}^{\circ} \mathrm{V} / l^{\circ} \ll$. B. de Abbaticia.

\section{$-4-$}

1308. enero 9. Valencia

Jaime II, rey de Aragón, abuselve a Ramón Berenguer, vecino de Alcoy, de la muerte de Domingo Bellvert ya que ésta se ha producido debido a un accidente no imputable al dicho Ramón Berenguer.

AMA. Cort del Justícia 1308-10, fol. 16́v.

Jacobus Dei gratia rex Aragonum, Valencie, Sardinie et Corsice, comesque Barchinone ac sancte roma / ne ecclesie vexillarius, amirantus et capitanus generalis, dilecto fidelibus suis procuratori ${ }^{\circ}(.$.$) / universis et singulis baiulis,$ iusticiis ac aliis officialibus nostris Regni Valencie presentibus fu/turis vel eorum loca tenentibus ad quos presentes pervenerint, salutem et dileccionem. Raymundus Be/rengarii, vicinus de Alcoy, presens exposuit coram nobis quod cum ipse simul cum quibusdam aliis / hominibus dicti loci temporibus retróactis in festo Natalis Domini, iret armatus per villam ipsam de Alcoy, causa aliquorum lodurum quos in ibi faciebat, et idem Raymundus Berengarii / teneret eurem suum evaginatum quidam de illis qui simul cum eo erant in ludis predictis / nomine Dominicus Belver per se feriendo in ensem dicti Raymudi Berengarii casualiter exticit / (...). De quo vulnere processu temporis racione ne- 
cligencia (sic) ipsius Dominici contigit eum mori / propter quod suplicavit nobis humiliter quod cum ipse de dicta morte in nulla existeret culpa fratris / et (...) ipsius mortui quia mors illa segute fuerunt casualiter nullam querimoniam vel denunciacio / nem fecerint contra eum dignaremur eidem super predictis remisionis gratiam facere specialem. Qua / suplicatione benigna admissa vobis dicimus et mandamus quatinus si predicta veritate nitantur $/{ }^{\circ}(.$.$) Raymun-$ dum Berengarii non teneatis in reguardo racione dicte mortis nec per inde $1(. .$.$) vel bonis suis questionem moveatis vel demandam aliquam faciatis. Quo-$ niam nos / (...) ut permititus (?) vera existunt omnem questionem et demandam et omnem penam civilem et / criminalem quam contra eum vel bona sua possemus penere vel infligere racione / predicte, sibi cum presenti carta nostra remictimus de gratia speciali.

Datum in Valencie $\mathrm{V} .{ }^{\circ} /$ idus ianuarii anno Domini millesimo trecentessimo septimo.

$$
-5-
$$

1308, febrero 16. Xàtiva

Jaime II, rey de Aragòn, ordena a los naturales de Alcoy que respondan de sus rendas a Jaufredia de Llúria ya que su hermano Rogeró, anterior señor de Alcoy, asi lo dispuso a cambio del castillo de Riciliani

AMA. Cort del Justícia 1308-10, fol. 18r - v

Jacobus Dei gratia rex Aragonum, Valencie, Sardinie et Corsice, comesque Barchinone ac sancte roma / ne ecciesie vexillarius, amirantus et capitanus / generalis, dilectis Petro Garcessi de Masones, Guillelmo de Pratis et fidelis Jacobi (?) Ça / guardia, manumesoribus nobilis Rogerii de Loria, quondam, salutem et dileccionem. Ex parte nobilis Jaufredine de Lauria, uxoris nobilis Roguerii de Sancto Severino, quondam, fili nobilis Thomasis de Santo (sic) Severino, comitis Mascisci, fuit nobis expositum quod inter ipsam / Jaufredinam ex unam partem et Rogeronum de Lauria, quondam, fratrem suum, seu procuratores suis / ad hoc speciale habentes mandatum ex altera super dote dicte Jaufredine et Castro Riciliani / scito in instaciato (?) tale pactum sive convenio intervenit, quod dictus Roge / ronus solvere dicte Jaufredine suisque heredibus pro dote sua mille sexcentas viginti quinqui / uncias aurei ponderes (?) generalis propter quod recepit a dicta Jaufredina iusoram quibus I de dicta dotis quantitate per dictum virum suus fuerat enim cautum. Necnon et de dicto castro / Riciliani per ipsam tenendo et possidendo cum terris, hominibus, redditibus, iuribus et perti / nenciis suis toto tempore vite sue, raccio- 
ne cuiusdam castri dictus Rogeronus tenebatur / in super tradere et tradi facere ex causa comcambii seu permutationis dicte Jaufredine / castrum de Alcoy, situm in Regno Valencie, cum homnibus, redditibus, iuribus et pertinenciis / suis. De quibus redditibus quos per manum suam habet percipere et habere dicta Jaufredine / habet retinere centum uncias auri convertendos in sus (sic) suos. Et si quid super / fuerit de redditibus dicti loci de Alcoy habet restituere heredibus prefati Rogeroni / fratri, et quod de fuerit de dicta quantitate centum unciarum aurei habet enim com / pleri et dari de bonis Rogeroni predicti tanto tepore quanto dictus Rogeronus vel heredes suis tenuerint castrum Riciliani predictum. De quibus omnibus predictis fuit in cancellaria / nostra (...) publicum instrumentum. Et cum asseratur dictam Jaufredinam non dum havuisse / possessionem dicti castri et ville de Alcoy, nec sibi traditam fuisse, nec homines dicti loci / respondeant de redditibus eiusdem, nec ipsa per manum suam aliqui recipiat de eisdem, / nobis humiliter suplicavit ut faceremus convenciones predictas ad impelari et sibi castrum / et villam predictam cum hominibus, iuribus, redditibus et pertinenciis suis tradi plenarie et $/ /$ (fol. $18 \mathrm{v}$ ) (...) suplicatione admissa nobis dicimus et mandamus quatenus predictum castrum et villa $(\ldots) /(\ldots)$ traditis plenarie potenter nobili Jaufredini $(. .) /.(\ldots)$ et possidendum ex dita causa. Mandantes presentis universis hominibus de Alcoy I quod dictus Jaufredine vel cuy ipsa voluerit loco sui respondeant de omnibus redditibus et iuribus dici loci.

Datum Xative XIIII. ${ }^{\circ}$ kalendas marcii anno Domini $\mathrm{M}^{\circ} \mathrm{CCC}{ }^{\circ}$ septimo.

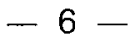

\section{8, febrero 17. Xàtiva}

Jaime II, rey de Aragón, ordena a los habitantes de Alcoy que cumplan las disposiciones que sobre sus rentas ha hecho a Rogeró de Llúria, anterior señor de Alcoy, a su hermana Jaufredina y que presten homenaje al noble Gombau de Entença, tutor de Berenguer de Llúria, actual señor de Alcoy.

AMA. Cort del Justícia 1308-10, fol. $20 \mathrm{r}$

Jacobus Dei gratia rex Aragonum, Valencie, Sardinie t Corsice / comesque Barchinone ac sancte romane ecclesie vexillarius, amirantus et capitaneus generalis, / universis hominibus habitantibus in loco de Alcoy et eius termino, salutem et gratiam. / Cum nos nobilem virum ac dilectum nostrum Gombaldum de Entençam in tutorem Berengarono / filio nobilis Rogerii de Loria, quondam, duxerimus assignandum. Ideo volumus ac vobis dicimus / et mandamus quatenus servatis obligationibus factis nobili Jafredine, filie nobilis Ro- 
gerii / supradicti per nobilem Rotgeronum fratrem dictem Jafredine de castro de Alcoy ac redditibus / et iuribus eiusdem, ut incarta inde facta latius continetur dicto nobili Gombaldo tanquam / tutori dicti pupilli homagium prestare curetis. Et hoc non differatis seu mutetis aliquam / rationem.

Datum Xative XIII. ${ }^{\circ}$ kalendas marcii anno Domini Millesimo CCC. ${ }^{\circ}$ septimo. 10.HIS.268

1309, mayo 30. Barcelona

Jaime II, rey de Aragón, ordena al justícia de Valencia que a todos aquellos que se han inscrito en la armada que comandará Bernat de Sarrià les sea prorrogado el plazo en el pago de sus deudas.

AMA. Cort del Justícia 1308-10, fol. 124r - v

Jacobus Dey gratia rex Aragonum, Valencie, Sardinie et Corsice, comesque Barchinone ac sancto romano ecclesie, / vexillarius, amirantus et capitanus generalis, dilecto suo Bernardo de Libiano, militi, salutem et dileccionem. Pro parte proborum / hominum et universitatis civitatis Valencie querelando propositum exticit coram nobis ${ }^{\circ}(.$.$) auctoritate / officii amiranrie (sic) in quo$ vices geritis dilecti amiranti et consiliarii nostri Bernardi de Sariano elongamento nomine / elongamenti conceditis aliquibus hominibus acordatis in presenti armata ne sua debita que non dolibet / in ipsis obligati appareant usque ad reditum viagii dicte armate solvere teneantur quod iusticie civita / tis predicte ne prohibatis hominum ad solvendum sua debita aliquot compellat totaliter in hiberis (?). Ex / quibus contra forum et rationem probi homines et universitas predicti multipliciter ad gravantur cumque de huiusmondi // (fol. 124v) elongamento concedendo vos vel aliquis alius noster $(. ..) /{ }^{\circ}(.$.$) debita ad que-$ mius preternos (...) pertinant (...) spectet mirantes duobus quot (?) talia facere I supersistis vobis dicimus et mandamus (...) quatenus a premissis omnino visis presentibus desistate nec de / cetero ipsa elongamenta facere attemptesis per ${ }^{\circ}(. .$.$) quipe mandamus iusticie Valencie vel eius / locum tenenti { }^{\circ}(.$.$) talia$ alongamenta si qua per nos ${ }^{\circ}(. .$.$) sunt servent aut teneant nec teneri aut / ser-$ vari faciat. Immo eadem irriter et anellet preterea elongamentum ${ }^{\circ}(.$.$) homini-$ bus acordatis / in dicta armata observari et teneri volumus dictum iusticie quatenus iuxta formam contentam in / (...) Regni Valencie fuerit observandum.

Datum Barchinone $1 \mathrm{II} .^{\circ}$ kalendas iunii anno Domini M. ${ }^{\circ} \mathrm{CCC}{ }^{\circ}$ nono. 
1309, julio 26. Cap de l'Aljub

Jaime II, rey de Aragón, prohibe a los justicias o a sus lugartenientes que encausen por motivos de deudas a Pere de Azagra o a algunos de sus 100 compañeros, ya que forman parte del ejército real en la campaña contra el Reino de Granada hasta que no vuelvan de dicha campaña.

AMA. Cort del Justícia 1308-10, fol. $129 \mathrm{r}$

Jacobus Dei gratia rex Aragonum... a tots los justícies o sos lochtinents que aquesta present / letra veuran. Sapien de nostra part que en P. de Çagra, almutacen nostre, va am (sic) nos en aquest / fet de Granada ab C companyons per que us deim e us manam que no destrengats nengun dels dits C hòmens per deute que deien ne les fermances qui per ells són tenguts de pagar entró / que sien venguts del dit viatge o altre manament aiats nostre.

Feta en lo Cap de l'Aljup / sots lo nostre segell secret XXVI dies anats de juliol anno Domini M CCC. ${ }^{\circ}$ nono.

\section{$-9-$}

1309, julio 26. Cap de l'Aljup

La misma disposición que la del documento anterior para Laportis Adalill o algunos de sus 100 compañeros.

AMA. Cort del Justícia 1308-10, fol. 129 r

Açò és treslat d'una letra del senyor rey en paper sagellada ab son sagell secret de la que / la teno és aytal:

Jacobus Dei gratia rex Aragonum... a tots los justícies o sos lochstinents que aquesta present / letra veuran. Sapien de la nostra part que Laportis Adalill va ab nos en aquest fet de Granada / ab C companyons per que us dehim e us manam que no destrengats nengú dels dits $C$ hòmens per / deute que deguen, ne les fermances qui per ells són tenguts de pagar entró que sien venguts / del dit viatge o altre manament haiats nostre.

Feta en lo Cap de l'Aljub sots lo nostre segell secret XXVI dies anats de juliyol (sic) anno Domini M. ${ }^{\circ} \mathrm{CCC}{ }^{\circ}$ nono. 
1309, julio 29. Cap de l'Aljub

Jaime II, rey de Aragón, ordena a los justicias y jurados que reunan la mayor cantidad posible de animales de carga y los envien a Elx donde está Bernat Marti encargado de reunir a todos estos animales para llevarlos al ejército real. Al mismo tiempo ordena que al portador de la carta se le faciliten las cabalgaduras que precise.

AMA. Cort del Justícia 1308-10, fol. 129r - v

Aço és traslat d'una letra del senyor rey en paper sagelaba ab son sagell secret, la tenor / de la qual és aytal:

En Jacme per la gràcia de Déu rey d'Aragó... als amats justícies, batlles $e$ jurats / als quals les presents vendran, salut e dilecció. Co ya d'altres vegades vos aiam escrit / per aquesta rahó, encara ha cadahun de vos, dehim e manam, així expresament com podem, que tant / tost vistes les presents nos enviets totes aquelles bèsties de bast que trobarets, aixi muls com /I (fol. 129r) ${ }^{\circ}(.$.$) e rocins que veurets { }^{\circ}(. .$.$) / carga, e aquestes fets anar a Elg$ hon trobarets Bernat Martí sobre asembler nostre / qui.ls darà çò que auram (...) els quitarà d'aquí a evant e açò manants a tots / aquels de les dites bèsties en pena de les persones.

Encara vos dehim e us manam que si per $/^{\circ}($...) Martí de la Boça, porter nostre, que aquí enviam ab la present carta aurà obs de mudar / bèstie ni bèsties que los lus (sic) donets a açò no mudets.

Data en lo Cap de l'Aljub sots / nostre sagell secret dimarts XXIX dies anats de juliol anno Domini Millesimo $\mathrm{CCC}{ }^{\circ}$ IX. ${ }^{\circ}$

1309, noviembre 4. Sitio de Almeria

Jaime II, rey de Aragón, a instancias y ruegos de na Jaufredina, hija de Roger de Llúria, absuelve a Ferrer Puig, vecino de Alcoy, de la muerte de Bernat Domènec vecino de Albaida.

AMA. Cort del Justícia 1308-10, fol. 164r

Nos Jacobus Dei gratia rex Aragonum, Valencie, Sardinie et Corsice ac comes Barchinone ad / (...) et instanciam nobilis Gaufredine, filie nobilis Rogerii de Loria, amiranti nostri (...) / per nos et nostros absolvimus ${ }^{\circ}(.$.$) , renun-$ 
ciamus ac ${ }^{\circ}(. .$.$) relexamus tibi Ferrario de Pudio, vici / no de Alcoy, et tuis$ ${ }^{\circ}(. .$.$) omnem questionem, peticionem seu demandam et (...) penam civilem$ $(. .) /.(\ldots)$ quamqueque quam contra te seu bona tua nos vel nostri possemus (...) / racione mortis Bernardis Dominici, vicini Albayde, de qua fuisti ${ }^{\circ}(.$.$) in-$ culpato (?) ${ }^{\circ}(.$.$) ita quod (...) / in dicta morte culpabilis fueris sive non tu vel$ bona tua non possitis per nos seu officiales nostri / (...) capi, detinere seu in iudicio (...) te ${ }^{\circ}(.$.$) / civiliter iusticie complementum. Mandantes per presentes$ universis et singulis (...) / presentibus (et) futuris quod absolutionem, deficionem et remisionem nostram (...) / tibi et tuis et faciant inviolabiliter aobservari et non contraveniant nec ${ }^{\circ}(.$.$) / ne permitant aliqua racione. In cuius rey testi-$ monium presentem cartam ${ }^{\circ}(. .$.$) / pendenti iusimus sigillari.$

Datum in obsidione civitati Almerie IIII. ${ }^{\circ}$ nonas november anno / Domini $\mathrm{M} .{ }^{\circ} \mathrm{CCC} .{ }^{\circ}$ nono. Enrichus.

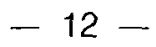

1314, enero 10. Valencia

Jaime II, rey de Aragón, reconoce deber a una serie de vecinos de Alcoy ciertas cantidades por los animales que le prestaron en su campaña de Almería.

AMA. Cort del Justícia 1321 , fols. $168 \mathrm{r}-169 \mathrm{~V}$

Die sabati XII kalendas aprilis.I

Hoc est translatum et fideliter sumptum a quandam litera domini regis sigillata / in dorso cere rubee cuius est tenor talis:

Jacobus Dei gratia rex Aragonum, Valencie, Sardinie et Corcisse, comesque Barchinone ac / sancte romane ecclesie vexillarius, amirantus et capitaneus generalis, fidelibus suis / collectori seu collectoribus quicumque fuerunt monetatici quod nos primo exigere et / habere contingat ab universitate hominum ville Xative, salutem et gratiam. Cum personis / subscriptis debenatur per curiam nostram quantitates pecunie infrascripte quas iam eis / alias asignaverimus super primis dinariis quos ab hominibus ville de Gandia racione // (fol. 168 v) subsidii vel alterius exactionis exigire nos contingeret ut per alia litera nostra te / noris qui sequitur continetur:

"Nos Jacobus Dey gratia rex Aragonum etc, atenden / tes quod per curiam nostram debentur vobis subscriptis hominibus de Alcoy quantitates / pecunie infrascripte cum albarano fidelis azemilarii nostri Bernardi Martini sub / sequitis: 
"Jo en Bernat Marti sobre azembler del senyor rey atorch e vench / de manifest que és degut als deius scrits homens d'Alcoy, és a saber, per loger I ferrar e esmena d'alcunes besties que tengueren el loger de la cort en lo viat / ge d'Almeria: Primerament an Bernat Giner per un mul seu que tenia en Jacme d'Oblites / e entra en loger lo dimecres XXV dies de juny e morí en lo setge d'Almeria lo / dimecres VI dies d'agost qui són XIII dies, fan a rahó de XII diners per cascun dia XIII sous/.

Item, li és degut per un peu de ferrar de tots los dies XIII, IIII diners, encara li és / degut per esmena del dit mul CC sous, e així és tot en suma çò que per la desus / dita rahó li és degut CC XIII sous, IIII diners.

Encara és degut a.n Johan de Fon / teś per un rocí seu qui en lo dit setge murí segons que pus largament en mon / libre dels albarans és contengut, CC LXXX II sous e VIII diners.

Encara és degut a.n Bernat Micó per una mula seua que.s perdé lo dimecres XVII dies de setembre / en la orta CC XXXVII sous IIII diners.

Encara és degut a.n Michell Picó per / un roci seu que morí en lo viatge com anaven ab la ost, C XXXIIII / sous IIII diners.

Encara és degut a.n Domingo Yvanyes per un mul seu qui.s perdé / en la orta d'Almeria, CC XLVII sous IIII diners.

Encara és degut a.n Matheu de Çagra per / una mula qui.s perdè el bovar d'Almeria, CC LXXX sous.

Encara és degut a.n Berenguer Maymó / per un mul seu que Pere Jordà d'Arenś se retench que no.I volch tornar a la / cort, CCCC IX sous IIII diners.

Encara a.n Ferrer de Vilabertran per un mul seu / que.I dit Pero Jordà vené ho alienà que no.I cobrà la cort, CC XCVII sous / IIII diners.

Encara a.n Guillem Berenguer per un mul e una mula escrits a ells el meu llibre // (fol. 169r) e cobrales don Johan de Vidaure, CCCC XVIII sous e VIII diners.

Encara a.n R. / d'Irles per una mula sus que cobrà com la host fo tornada del viatge, $\mathrm{CC} \mid \mathrm{X}$ sous / III diners.

Encara a.n Bernat Rovira per un mul seu que cobrà, lo qual tench don I Pero Martinis de Luna, CCIX sous IIII diners.

Encara a.n Guillem Guerau e a.n Bernat Guerau / per dos muls llurs que pensava Gil Martinez els cobraren d'en Pero Martinis de / Luna, CCCC XVIII sous VIII diners. 
Encara a.n Pere Centonge per un mul seu que pen / sava Pere Calp, lo qual cobrà d'en Pero Martinez de Luna, CC IX sous IIII diners.

Encara a.n Barceló Renau per un mul seu que pensava Martí Botí (?) lo qual li fo liçen / ciat que.l tragués de la ost ab voluntat del senyor rey, $\mathrm{XCl}$ sous VIII diners.

Encara / en Domingo Guardiola per un mul seu que cobrà XCl sous VIII diners.

Encara a.n Berenguer / Barberà per un mul seu que cobrà XCl sous VIII diners.

Encara a.n Domingo Muntllor / per un mul seu que cobrà, $\mathrm{XCl}$ sous VIII diners.

Encara a n'Andreu Marti per un ase seu que co / bra XLV sus $X$ diners.

Encara a.n Jacme Pardines per un ase que cobrà, $X L / V$ sous $X$ diners.

Encara a.n Vidal Berber per un ase seu que cobrà ho.I to liçenciat / XLV sous $X$ diners.

E aixi és tot en suma çò que als desus dits hòmens d'Alcoy és / degut per la desus dita rahó, segons que el mon libre dels albarans pus larga / ment és contengut, quatuor mille septuaginta unum solidos et duo dinariis barchinones, / de la qual cosa los fiu aquest albarà segellat ab mon sagell escrit en València, dimecres / XVII dies del mes de febrer, anno Domini Millesimo $\operatorname{CCC} \times{ }^{\circ}{ }^{\prime}$

Idcirco per presentem cartam nostram / asignamus vobis hominibus supradictis quantitates pecunie superius compresatas super primis / dinariis quos ab hom nibus ville de Gandie, ratione subsidii vel alterius exaccionis / exigere nos contingat. Mandamus itaque per presentem fideli tesausaurio nostro aut I cuicumque collectori dictorum denariorum quod vobis hominibus supradictis solvat dictis pecunie / quantitates pro ut in albarano inserto superius distincte. Solutis tamen asignationibus / prius factis et facta solucionem presentem a vobis recuperet cum apocha seu apochis // (fol. 159v) de soluto vos vero restituistis nunc in cancellare nostre albaranum predictum / quod fuit ibi pro cautela curie lateratum.

Datum Valencie V. ${ }^{\circ}$ kalendas aprilis anno / Domini M. CCC XII. ${ }^{\circ}$

Et de dictis quantitatibus non fuerint dictis personis aliquid ex / solutum ut costat per resignationem litere superius inserte et per certificationem / et magistris racionalis curie nostram factam in cancellare nostra que fuerunt / nunc 
in dicta cancellare restitute pro cautela curie laterate. Idcirco per presentes / vobis dicimus et mandamus quatenus denariis dicti monetatici dicti loci / Xative tribuatis et solvatis prefatis personis quantitates pecunie supradictis sint / superius continetur. Solutis tamen assignationnibus prius factis et facta solucione / recuperetis presentem literam cum apocha de soluto.

Datum Valencie IIII. ${ }^{\circ}$ idus ianu / arii anno Domini Millesimo CCC XIII. ${ }^{\circ}$ Exa. M.

\section{1, marzo 13. Valencia}

Jaime II, rey de Aragón, ordena a los tutores de Roger de Llúria, senyor de Alcoy, que respeten los derechos judiciales de Simó Guillem de Vilafranca en su pleito con Gondiçalbo Ivañez.

AMA. Cort del Justícia 1321, fols. 171v - 172r

Comperech en cort davant lo justícia en Gondiçalbo Ivanyez e presenta a aquell una carta / del senyor rey uberta e sagellada el dos ab lo sagell del dit senyor e una letra / del noble en Roger de Luria les tenors de les quals és aytal:

Jacobus Dey gratia rex Aragonum, Valencie, Sardinie et Corsice, comesque Barchinne ac / sancte romane ecclessie vexillarius, amirantus et capitanus generalis, nobili et dilecto / Petro de Queralto gerenti vices procuratoris in regno Valencie pro inclito infante Alfon / so (...) primogenito et generali procuratori nostro, salutem et dileccionem. Nuper provenit ad / nostram audienciam quod nobilis Rogeronis de Lauria et curatores eius gravaverant / Simoni Guillemi de Villafrancha in quibusdam processus factus inter Gondiçalbum Hivanyes // (fol. 172 r) vicinum de Alcoy ex una parte et eumdem Simonem Guillelmi ex altera super grimoniis (sic) civilibus / super quibus nos supplicatione ex parte dicti Simonis Guillelmi nobis oblata cognovimus et decre / vimus ipsos processus de iure et foro Valencie, fore iustos cum civilis iurediccione locorum / dicti nobili et nominanti in locis de Cocentaine et de Alcoy ubi lectigaverunt nostatur secundum / forum Valencie ad prestandum nobile Rogeronum super civili iurisdiccione quam habet et habere de / bet pro habitatores dictorum locorum vel quocumque alios ubi convenientes uniuscumque condicio I nis existant ${ }^{\circ}(.$.$) perturbari. Immo ipsum et curatores, procuratores et ofi-$ cials suos / manucteneatis (?) et etiam defendatis.

Datum Valencie III idus marcii anno Domini Millesimo CCC. ${ }^{\circ}$ XX. 


\section{2, mayo 6. Xàtiva}

Alfonso $\mathrm{N}$, rey de Aragón, a instancias de su consejero Bernat de Sarrià, ordena al justicia y baile de Alcoy que liberen a un sarraceno, vasallo suyo, llamado Abdala, vecino de la alquería de Polop, que había sido preso por un almogaver llamado Miquel Maçana.

AMA. Cort del Justícia 1332, sin foliar

Alfonsus Dei gratia ex Aragonum, Valencie, Sardinie et Corsice ac comes Barchinone, fi / delibus nostris iusticie et baiulo de Alcoy vel eorum loca tenentibus, salutem et gratiam. Ex / positum fuit nobis per nobilem et dilectum consiliarium nostrum Bernardum de Sarriano quod / homines dicti loci de Alcoy ceperunt / quondam saracenum vocatum Abdala de Polop quin re / ceperint ab illis quos cepit Miquel Maçana almugacen ${ }^{\circ}(. .$.$) unde cum ut dicto$ no / bilis aserit dicto omines iam dictum saracenum infra (?) terram et dominationem nostram / ceperint et proptere non debeant ipsum captum detinere. Idcirco ac dictis nobilis supli / cationem et quia si sic est non intendimus dictum saracenum capi debere vobis. / Dicimus et mandamus quatenus iam dictum saracenum cum bonis suis liberetis seu liberari lico / faciatis.

Datm Xative $11 .{ }^{\circ}$ nonas madii anno Domini $M .^{\circ} \mathrm{CCC} .{ }^{\circ} \mathrm{XXX}$ secundo.

$$
-15-
$$

1355, agosto 21. Càller

Pedro IV, rey de Aragón, otorga a Pere de Xérica los lugares de Navarrés, Quesa, Ibi, Torre de les Maçanes, Margarida y El Llombo

AMA. Protocol Notarial 1356, sin foliar

Pateat cunc / tis quod nos Petrus Dei gratia rex Aragonum, Valencie, Maioricarum, Sardine / Corsiçe (sic) comesque Barchinobe, Rossilione et Ciritane (sic), servicia per / vos nobilem et dilectum consiliarium nostrum Petrum dominum / de Exerica, domicellum nobis, inpensa specialiter in hoc Sardine vi / agio laudabiliter atque prompte multimode merverunt ut / vos pro inde retributionis gratia prosecamur hic est quod in aliqua / lem remunerationem dictorum serviciorum. Tenore presentis publi (...) ci instrumenti perpetuis temporibus valituri gratis ex certa scientia et / spontanea voluntate pura profecta et irrevocabi donacione quod / dicitur inter vivos per nos et successores nostros 
perpetuo damus et conce / dimus vobis, dicto nobili et vestris successoribus inperpetuum (...) / (...) et iuxta consuetudinem Cathalonie honeratum tamen / et absque alicuius servicii prestationem potestate excepta (...) / de subscriptis quod nobis et nostris damus in feudum vobis et / vestris dare tenebamini vos et vestri omnem iurisdiccionem al / tam et baxam et merum ac mixtum imperium quas et quod / nos habemus et habere debemus et per nos et nostros officiales seu comissarios uti consuevimus in locis de Navarres, de Quesa // de Ibi, de Turri de les Maçanes, de Margali / ta et del Lombo seu eorum terminis appendicis et pertinen / ciis universis in Regno Valencie constitutis quod fuerunt nobi / lis Beatricis de Loria, matris vestre quondam. Ita quod a modo huius / pretextu donacionis in feudum vos et vestri successores perpe / tuo per nos et nostros officiales aut comissarios possitis / et nobis liceat exercendo dictam omnimodam iurisdiccio / nem altam et baxam ac merum et mixtum imperium punire / iuxta eorum demerita delinquentes quoscumque intra dicta lo / ca seu eurom terminis appendicia aut pertinentias pro ut / exhigerint criminum qualitates possitis inqua in dictis / locis et quolibet ipsorum et in eorum terminis et pertinenciiis ubi / cumque volueritis furcas et castellos erigere et / tenere ad vestri et vestrorum libitum voluntatis. Hanc / itaque donacionem in feudum per nos et nostros facimus vobis / et vestris perpetue sicut melius dici potest et intelligi / atque scribi ab bonum et sanum intellectum comodumque / et salvamentum vestri et vestrorum. Et extrahentes / predicta omnia et singula que nobis supradamus in feudum / de iure domino et posse nostri et nostrorum eadem in ius dominum et posse mitimus et transferimus / vestri et vestrorum irrevocabiliter pleno iure. Induncentes vos de predictis omni / bus et singulis in possessionem corporalem seu quasi omnium // predictorum ad habendum, tenendum omnique tempore pacifie pos / sidendum pro ut melius per nos vobis data sunt et superius / continetur. Et pro ut feuda que a nobis tenentur iuxta usa / ticos Barchinone et constituciones Gathalonie ge I nerales vendi consueverunt et possunt promitentos vobis / quod trademus vobis vel cuy volueritis loco vestri posse / ssionem corporalem seu quasi omnimum predictorum. Et nichillo / minus damus et concedimus vobis auctoritatem, licenciam et / plenum posse quod vos per nos vel alium nomine nostre auctori / tate vestra propia possitis possessionem seu quasi omnimum / predictorum et singulorum libere aprehendere et aprehensam lice / re retinere. Nos enim donet vobis dictam possessionem / tradiderimus vel vos eam aprehendiretis constitumus vos interim / predicta omnia et singula per vobis et vestro nomine precarie possidere. / Et ex causa huius donacionis in feudum cedimus per / nos et nostros vobis et vestris perpetuo omnia iura omnesque / acciones realies et personales mixtas, utiles et directas et alias quascumque nobis competentes et competere de / bentes in predictis omnibus et singulis et 
contra quascumque / personas et res recione eorum. Quibus iuribus et ac accionibus / possitis vos et vestri et expediri agendo / et defendendo et alia comodolibet in indicione (?) // quem ad modum nos possemus autem huiusmodi vel extra // in feudum / donacionem et iurium cessionem.

Mandantes tenore / huius publici instrumenti quod vicem (...) gerere volumus (?) / in hac parte universis et singulis hominibus et feminis in / dictis locis de Navarres, de Quesa, de Ibi, de Turri / de les Maçanes, de Margalita et del Lombo et in eorum termi / nis pertinenciis habitantibus et habitaturis quod nos et / nostros que ad hec (sic) que nobis et nostris in feudum damus vos et vestros / pro dominis eorum habeant et teneant vobisque et vestris / pateant et respondeant in et super omnibus et singulis / in et super quibus nobis autem presentem donacionem de / bebant et tenebantur respondere ac etiam obedire ac pro / predictis vobis et vestris homagium faciant et fidelitatis etiam / iuramentum que illis qui pro nobis feuda tenent sunt fieri / asueta. Nos enim absolvimus de presenti omnes singulos homines et feminas predictos ab omni homagio et aliis quibus nobis astricti sunt pro predictis que vobis in / feudum damus, et sub tali pacto dictam dona / cionem in feudum nos et nostros facimus que vos et vestri / de hiis que nobis damus in feudum teneamini irati l et pactati nobis et vestris dare potestatem totius (?) quotiens per nos vel nostros successores fueritis requisti iuxta / usaticos Barchinone et constitutiones Cathalonie generales. Ad hoc // (1) gratiarum accione recipiens a vobis dicto domino (...) / huiusmodi in feudum donacionem per me et meos (...) / et firma stipulatione promito vobis dicto domino rege / presenti recipienti et vestris quod ego et mei pro eodem feudo / vobis dicto domino regi et vestris iuramentum et homagium fa / ciemus et potestatem debimus irati et paccati per vos dictum dominum regem superius est largius expressatus (?). / Et nichilominus tactis per me sacrosanctis quatuor e / vangeliis coram me possitis iuro et pro predicto feudo fa / cio vobis homagium ore et manibus comendatum iuxta usa / ticos et constituiones premissis. Et nos rex / predictus recipientes a vobis dicto nobili iuramentum / et homagium antedicta de dicto feudo per tradicionem unius / eusis vos presencialiter investimus in ipso feudo / iure nostro et quolibet alieno in omnibus semper salvo.

Man / dantes cum hoc eodem publico instrumento vicem epistolem / in se gerenti inclito et magnifico infanti Johanni / nostro primogenito carissimo, duci Gerundem (...) / Cervare, et nostris et suis universis et singulis successoribus et officialibus / presentibus et futuris quod huiusmodi in feudum dopa / cionem nobis et nostris teneant perpetuo et observent et // (1) contravenire

(1)Falta una línea que aparece cortada en el texto. 
permitant aliqua racione. Ivenius rei / testimonium presens instrumentum publicum fueri iussimus / nostre magistatis sigillo in pendenti munitum.

Datum / et actum in castro Calleri die vicesima prima / augusti anno a Nativitate Domini $\mathrm{M}^{\circ} \mathrm{CC} .{ }^{\circ}$ quinquagesimo quinto. / Exa rus.

Sig(signo)num Petri Dei gratia regis / Aragonum, Valencie, Maioricarum, Sardinie et Corssice, co / mitisque Barchinone, Rossilione et Ciritane, qui hoc / laudamus, concedimus et firmamus.

Sig(signo)num Petri domini / de Exerica antedicti qui laudo, concedo et iuro ac ho / magium facio.

Testes huius rei sunt: nobilis Ber / nardus de Capraria, armatarum domini regis generalis ca (...) pitaneus, consiliarius et Garcias Luppi de Cetina / uxerinus armatorum dicti domini regis.

Sig(signo)num / Mathei Adriani prothonotarii sigilo tenentis dicti domini regis l et regia auctoritate notarii publici per totam terram et domina / cionem eiusdem qui predictis interfuit et ea scribi fecit cum / raso et escripto in tertia linea consuetudinem Cathalonie et / in quinta quod fuerunt et clausit.

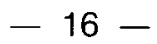

1356, enero 22. Cáller

Pedro $N$, rey de Aragón, otorga ciertas franquicias a todo aquél que se enrole en la armada fletada para volver a sus reinos peninsulares.

AMA. Llibre del Procurador General 1353-55, sin foliar

Nos Petrus Dei gratia / rex Aragonum, Valencie, Maioricarum, Sardinie et Corsice, comesque Barchinone, Ro / silionis et Ceritane, cum propter regressum nostrum quem in brevi Deo dante / facere debemus ad regna nostra ultra marina, ad hoc ut (...)/ valeamus et aliis de causis nos oporteat arnatam (sic) facere de persone. Idcirco / in favorem ipsius armate cum presenti carta nostra elongamus ge / neraliter omnes illos qui in dicta armata nostra se acordaverint et in partibus / istis cum nostris galeis meaverint. Necnon debitores et fideiussores pro et / cum eis obligatos et bona eorum penis et usuris cessantibus quibuscumque ab omnibus / et singulis debitis quod per eos debeantur quibuscumque pesonis tam christiani quam / iudeis et sarracenis quacumque personis tam christiani quam / iudeis et sarracenis quacumque racione seu causa. Preterea guidamus et / asecuramus eosdem ab omnibus et singulis excessibus et criminibus seu de / veretis per eos quocumque modo com- 
missus dum tamen non sunt preditores // bausatores de sodomice, fractores itinerum, falsatores monete, comiten / tes lese magestatis nec aliis armatis fugerint aut de morte per / petrata in persona abbatis sancti Cucufatis inculpati non fuerint.

Mandan / tes cum presenti tenenti locum nostri necnon gubernatoribus, procuratoribus et / aliisque universis et singulis oficialibus nostris presentibus et futuris vel loca / tenentibus eorundem quod elogamentum et futuris nostrum huiusmodi quod / durare et valere volumus dum dicta nostra armata duraverit et postea / per unum annum continue subsequentem. Et super quocumque modo tangentibus per tempus superius expresatum / teneant omnino de et observent et contra non veniant nec aliquem venire / permitant aliqua racione in rei testimonium presentem fieri iussimus nostro / sigillo (...).

Datum in castro Catllari XXII die ianuarii ano / Domini $\mathrm{M} .{ }^{\circ} \mathrm{CCC}{ }^{\circ}$ quinquagesimo quinto.

\section{$-17-$}

1356, abril 12. Sant Mateu

Pedro IV, rey de Aragón, ordena a los lugares de Alcoy, Calp, Altea, Vall de Seta y Vall de Travadell que presten homenaje de fidelidad a Francesc d'Esplugues, tutor de Jofre de Jamvilla, hijo de Nicolau de Jamvilla, conde de Terranova.

AMA. Protocol Notarial 1356, fols. $69 \mathrm{v}-70 \mathrm{r}$

Petrus Dei gratia rex Aragonum, Valencie, Sardinie et / Corsice, comesque Barchinone, Rossilionis et Ceritane, fidelibus nostris / universis et singullis hominibus habitatoribus locorum de Alcoy, termini / de Calp, de Altea et vallium de Seta et de Travadell, salutem et gratiam. Ad instanciam fidelis nostri Francisci Desplugues, tutoris nobilis / Jaufredi de Jamvilla, filii et heredis nobilis Nicholai de Jamvilla / quondam comitis de Terranove, vobis dicimus et mandamus quatenus dicti tutori dicto / nomine predictis locis, faciatis homagium fidelitatis salvo tamen iure / nostro nobis quomolibet pertinenti, in castris et locis superius nomina / tis quacumque opposicione facta in contrarium per nostrum fischalem procura / torem in aliquo non obstante.

Datum in villa Sancti Mathei sub // (fol. 70r) nostro sigillo secreto XII die aprilis anno a Nativitate Domini $\mathrm{M} .{ }^{\circ} \mathrm{CCC} .{ }^{\circ} /$ quinquagesimo sexto. 
1356, octubre 30 . Montesa

Pedro IV, rey de Aragón, debido a la necesidad de dinero que tiene para hacer frente a la guerra contra Castilla, autoriza a Gilabert de Centelles y a Barenguer de Codinacs que puedan vender propiedades y derechos suyos.

AMA. Protocol Notarial 1356, sin foliar

Nos Petrus Dei gratia, rex Aragonum, Valencie, Maioricarum, Sardinie et Corsice, comesque Barchinone, Rossilione et Ciritane, constiruimus et ordimamus certos / et speciales procuratores nostros vos nobilem et dilectos con / siliarios nostros Gilabertum de Centillis et Berengarius de / Codinachs, magistrum racionalem curie nostre et (...) / nostrum insolidum. Itaquod occupantis (...) non / existat sed quod per unum inceptum fuerit per alium me / diari persequi valeat et finiri ad recipiendum mutuo / vel comandam quascumque peccunie quantitates quas inten / deritis necessarias vel utiles esse negociis guerre / quam habemus cum rege Castelle. Et per ipsis quantitatibus / peccunie vel comanda reçeptis (sic) obligandum specialiter / certs redditus aut certa loca vel iura iura nostra et generaliter omnia bona nostra. Et ad submitendum vos nomine / nostro foro et districtui eglesiastico (sic) cum sacramen / to et pena excuminicationis et aliis penis et cautelis // renunciatonibus et obligationibus de quibus vobis ${ }^{\circ}(.$.$) / et cum mutuo vel comanda dantibus { }^{\circ}(.$. con / venire. Necnon etiam ad vendendum ${ }^{\circ}(.$.$) predictorum / per vobis et$ nomine nostro loca, redditus, iuridicciones et / quevis alia iura nostra ad certum (?) tempus longum vel / breve ad vitam hominis vel etiam ad inperpetuum / illis personis et per illo precio seu preciis cum quibus / et de quibus poteritis convenire. Concedentes vobis et utrique nostrum potestatem plenaria emptorem sive / emptores in possesionem inducendi et concedendi eisdem / licenciam aprehendendi ipsam possesionem eorum / propia auctoritate. Et de eniccione cavendi et per eniccione / omnia nostra bona specialiter et generaliter obligandi et / fideiussores per ipsa eniccione dandi et hominem seu homines / locorum que vendideritis a sacramento, homagio / et fidelitate liberandi, et eisdem in inungendi et mandandi et etiam si opus fuerit compellendi eosdem / ut emptori seu emptoris de ipsis iuribus / venditis respondeant et obediant eisque etiam / sacramentum et homagium ac fidelitate et cunc / ta alia adque tenevetur faciant et prestent et / iuramentum super predictis omnibus et singulis per vobis / et in animam nostram prestandis, et generaliter / omnia alia et singula faciendi et libere exercendi / que contractione et aliorum ominum 
et singulorum predictorum $/ /^{\circ}(.$.$) et natura (?) exhigent et requirent et de qui-$ bus etiam / cum contrahentibus conveneritus et que etiam vos facere et exer / cerepossemus si personaliter ad (...). Et etiam si mandatum / exhigant speciale et sint maiora graviora et magis ar / dua superius expressatis.

Conferentes vobis et utrique vestrum / liberam et generalem administracionem cum facultate plenis / suma super omnibus et singulis supradictis ac etiam permiten / tes sub vestra fide regia et virtute iuramenti a nobis / corporaliter (?) presenti. Nos ratum et firmum perpetuo (...) quatenus / quod super predictis omnibus et singulis vos et utrumque vestrum / actum (...) fuerit ac quomodolibet procuratum sub bonorum / nostrorum ominum ypotecha quantitates vero / peccunie quas excepcione mutui vel comande et ex pre / cio seu preciis predictorum habueritis converti per vos aut / deputandum seu deputandos a vobis in negociis / dicte guerre iuxta et ad vestri ordinacionem et ar / bitrium volumus et inbemus. In cuius rei testi / monium presentem fieri (?) iussimus nostro sigillo apen / dicio munita.

Actum est hoc in villa Montesoni / XXX die octobris anno a Nativitate Domini $\mathrm{M} .{ }^{\circ} \mathrm{CCC}{ }^{\circ}$ quinqua / gesimo sexto, nostrique regiminis vicesimo primo. Visa / Ratio.

Sig(signo) Petri Dei gratia regis / Aragonum, Valencie, Maioricarum, Sardinie et Cor / sice, comitusque Barchinone, Rossilionis et $\mathrm{Ce} /$ ritane, qui hoc concedemus, firmamus et iuramus.

Testes / huius rei sunt nobilis Bernardus de Capraria, Luppus / de Gurrea et Matheus Mercerii, camarlengi, Berengarius de Palacio et Petrus Jordani Durries, ma / iordomus, milites et consiliarii domini regis.

Sig(signo) / mihi Jacobi Castillionis, scriptoris serenissimi principis et / domini domini (sic) regis Aragonum et eius auctoritate notarii publici per totam / terram dominacionem suam qui predictis interfui et hoc de eius / mandato scribi, feci cum raso et emendato in linea prima / ubi dicitur Sardinie et Corsice et in linea XVII ubi / emendatur dicio munita actum est hoc in villa Montesoni / et clausi.

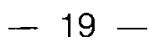

1361, mayo 18. València

Pedro IV, rey de Aragón, comunica a sus oficiales que ha firmado en Calatayud una tregua con el rey de Castilla al mismo tiempo que comunica que castigará severamente a todos aquellos que quebranten la dicha tregua.

AMA. Llibre del Procurador General 1359-62, fol. 110r - v 
De nos en Guillem Colom, procurador general per la molt alta e excellent / senyora, la senyora reyna d'Aragó en lo Regne de València, a l'hon / rat en Guerau Domènec, tinentloch nostre del riu de Xúquer enllà, saluts / e dilecció. Sapiats que.I senyor rey ha tramés la letra infrasegüent:

En Pere per la gràcia de Déu rey d'Aragó, de València, de Malorques, de Cerdenya / e de Corçega e comte de Barçelona (sic), de Roselló e de Cerdanya, als a / mats e feels nostres en Garcia de Loriç, portanveus de gobernador / general e en Pero Boyl, cavallers (sic) batlle general del Regne de València / e a lurs lochtinents, saluts e dilecció. Com entre nos e lo rey de Castella / sia fermada pau perpetual la qual és publicada ací en Cala / tayu, per manament nostre ab veu de crida e en loch de çà hon és // (fol. 110v) lo rey de Castella e vullam així com està en rahó e senblanment sia pu / blicada de vos de / him e manam expresament e de certa acientia que, en cotinent, ab veu de crida / façats solempnialment pública la dita pau ab imposició de pena de / cors e de béns a tothm de qualque condició sia que trenacarà la dita pau / e contra aquella faria en alguna manera, ans tots nostres sotmeses tin / guen e observen fermament la dita pau, no faen mal ni dan a sotsme / soso del rey de Castella en persones e béns, sabens que si.l contrari fahien serien punits en les dites penes e altres qui.s deuen inflingir a trencador / de pau donada per son rey, princep e senyor.

Datum en Calatayu sots nostre segell secret a XVIII dies de maig en l'any de la nativitat de / nostre sentor M CCC LXI. 